AperTO - Archivio Istituzionale Open Access dell'Università di Torino

\title{
A social way to experience a scientific event: Twitter use at the 7th European Public Health Conference
}

\section{This is the author's manuscript}

Original Citation:

Availability:

This version is available http://hdl.handle.net/2318/1570954

since 2016-06-23T09:56:03Z

Published version:

DOI:10.1177/1403494815612932

Terms of use:

Open Access

Anyone can freely access the full text of works made available as "Open Access". Works made available under a Creative Commons license can be used according to the terms and conditions of said license. Use of all other works requires consent of the right holder (author or publisher) if not exempted from copyright protection by the applicable law. 


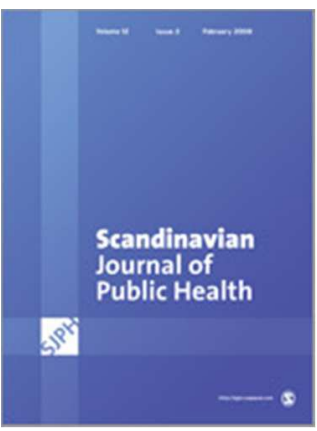

\section{A social way to experience a scientific event: Twitter use at the 7th European Public Health Conference}

\begin{tabular}{|r|l|}
\hline Journal: & Scandinavian Journal of Public Health \\
\hline Manuscript ID: & Draft \\
\hline Manuscript Type: & Original Article \\
\hline Date Submitted by the Author: & n/a \\
\hline Complete List of Authors: & $\begin{array}{l}\text { Bert, Fabrizio; University of Torino, Department of Public Health Sciences } \\
\text { Zeegers Paget, Dineke; EUPHA Office, } \\
\text { Scaioli, Giacomo; University of Torino, Department of Public Health } \\
\text { Sciences }\end{array}$ \\
\hline Problem Areas and Research: & Other \\
\hline Discipline: & Prevention and Health Promotion \\
\hline Methodology: & Quantitative - Qualitative combined \\
\hline &
\end{tabular}

\section{SCHOLARONE ${ }^{m}$ \\ Manuscripts}


1

2

3

4

5

6

7

8

9

10

11

12

13

14

15

16

17

18

19

20

21

22

23

24

25

26

27

28

29

30

31

32

33

34

35

36

37

38

39

40

41

42

43

44

45

46

47

48

49

50

51

52

53

54

55

56

57

58

59

60

Title

A social way to experience a scientific event: Twitter use at the $7^{\text {th }}$ European Public Health Conference

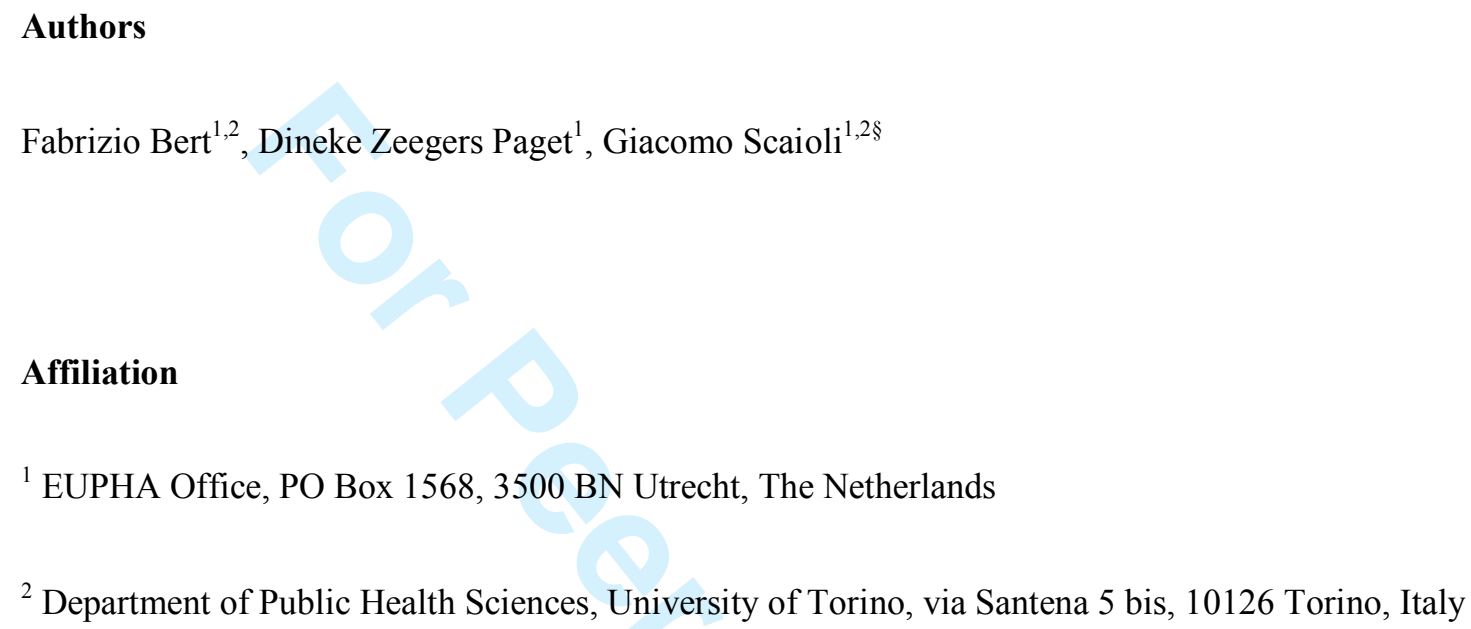

${ }^{2}$ Department of Public Health Sciences, University of Torino, via Santena 5 bis, 10126 Torino, Italy

\section{Corresponding Author}

${ }^{\S}$ Giacomo Scaioli

Department of Public Health, University of Turin

via Santena 5 bis, 10126 Turin, Italy

Tel: +390116705837 , Fax: +390116705889

e-mail: giacomo.scaioli@unito.it

Word count: 2589 


\title{
Abstract
}

\begin{abstract}
Aims
Many studies analysed Twitter's use by attendees of scientific meetings and the characteristics of conference-related messages and most active attendees. Despite these previous reports, to date no studies have described the use of Twitter during Public Health conferences. For this reason, we decided to perform an analysis of Twitter's use during the 7th European Public Health (EPH) Conference (Glasgow 19-22 November 2014).
\end{abstract}

\section{Methods}

All the tweets published from 21 July to 2 December 2014 and including the hashtag \#ephglasgow were retrieved and several information (author, date, retweets, favourites, mentions, presence of pictures and/or external links, content type and topics) were analysed using Stata MP11.

\section{Results}

A total of 1067 tweets with the hashtag \#ephglasgow were retrieved, $86.3 \%$ of these were tweeted during the conference. A total of 209 single accounts tweeted, pictures were present in $29.7 \%$ tweets while external links were published in $13.8 \%$. Conference speakers were mentioned in around $30 \%$ of tweets. Almost the $60 \%$ of the tweets had a session-related content. Considering only the session-related tweets, one third had as main topic "Health inequalities and migrant and ethnic minority health", while $20 \%$ were "Health policy and health economics" oriented.

\section{Conclusions}

Twitter's use during conferences is a growing phenomenon that allows public health professionals to be informed on all aspects of conference. Meeting's organisers have to promote online discussion and conference-related knowledge dissemination. Further studies are needed to highlight potential and issues of this communication tool, especially in the multidisciplinary public health field.

Keywords: Social media; Twitter; Public Health; Conference. 


\section{Introduction}

The use of social media, defined as "websites and applications that enable users to create and share content or to participate in social networking" [1], is increasing year after year [2,3]. Twitter, a platform that allow users to write short messages (up to 140 characters) is one of the most popular social media, with 284 million monthly active users and 500 million tweets sent per day [4]. In recent years, Twitter has become a useful tool for medical and scientific purposes [5-8]. A particular application of Twitter is its use during scientific conferences. The potential of Twitter in increasing networking skills, attendees connectivity, participation in debates and knowledge sharing is largely recognized [9.10].

Twitter enables the creation of an hashtag, that is a keyword (or unspaced phrase) preceded by the symbol "\#”, by which it is possible to identify all the tweets related to a specific topic [11]. Many conference organizers have started creating an official hashtag in order to identify all the tweets related to the specific conference [12-14].

Several studies have analysed the use of Twitter by attendees of scientific meetings, assessing the total use of this platform, the characteristics of the conference-related messages, and the most "productive" attendees [12-22]. For example, Radmanesh and Kotsenas analysed Twitter use during the 2014 annual meeting of the American Society of Neuroradiology, showing the average numbers of tweets per day and the total number of users stratified for professional category [13]. In another study Mishori et al. analysed public tweets coming from the 2013 STFM (Family Medicine) Annual Spring Conference to see who was talking about the conference and in what ways [12]. Wilkinson et al., instead, observed the trends variation in the use of Twitter at eight urology conferences that took place in 2013 [14]. Despite these previous reports, to date no studies have described the use of Twitter during Public Health conferences.

For this reason, we decided to perform an analysis of the use of Twitter during the $7^{\text {th }}$ European Public Health (EPH) Conference that was attended by more than 1500 attendees and took place in Glasgow, Scotland (UK) from 19 to 22 November 2014 [23]. The EPH Conference is an annual scientific meeting addressed to all public health and health services professionals and students worldwide. The conference is initiated by the European Public Health Association (EUPHA), and organised in collaboration with other partners [24]. In July 2014, the official hashtag \#ephglasgow was created and tweeted for the first time by 
the conference organisers, and during the conference all the attendees were invited to include this hashtag in their tweets.

The aim of the present paper is to describe quantitatively and qualitatively all the tweets that included the official hashtag of the EPH Conference, to evaluate how much this social media was used during this meeting and which were the most active users.

\section{Methods}

All the tweets that included the hashtag \#ephglasgow were retrieved from the website www.twitter.com, by using the tool "search on Twitter" [25]. Tweets published from 21 July 2014 (day in which the hashtag \#ephglasgow appeared for the first time) to 2 December 2014 (ten days after the end of the conference) were included in our study. For each tweet, information about the author, the day in which the tweet was sent, the presence of pictures and/or external links, how many times the tweets from any account was amplified or emphasized by retweeting or favouring, the mention of any other twitter account (by using the symbol @) and the language of the tweet (English/other languages) were retrieved by two independent researchers. The same two researchers manually analysed the text of each tweet published, retrieving information about any mention of conference speakers in the text. Speakers were defined as all the people that were talking to an audience during pre conferences, plenary sessions, workshops, oral, pitch and poster presentations.

Furthermore, all the tweets were categorised as follows, on the basis of previous studies on this topic $[13,15,21]:$

1) Session-related: content related to a conference session (impressions, quotes, other). E.g. "Margaret Whitehead recommending the EU funded \#demetriq at \#ephglasgow showing introduction of UK minimum wage improved \#mentalhealth";

2) Social: not related to the content of the sessions, (jokes, humour, social relations). E.g. "Did you meet Sir Roger the Elephant at Kelvingrove museum last night? \#ephglasgow \#ephglasgowquiz @EPHconference";

3) Logistic: information given to attendees about sessions or organizational aspects. E.g. "Meet \& Greet \#ephglasgow w/ Presidents Sections Environment, Health Promotion, Practice \& Policy, Chronic Diseases at @EUPHActs stand, 12:15"; 
4) Advertising: commercial tweets, promotion of products. E.g. "Visit our exhibition stand @EPHconference for free access \& to find out more about our books \& journals \#ephglasgow";

5) Scientific promotion: promotion of papers and scientific works. E.g. "Very interesting @PLOSONE @ rickwahs paper presented \#ephglasgow on decommodification \& health ineq by welfare regime http://www.plosone.org/article/info...”;

6) Other: tweets not related to the other five categories.

The "session-related" tweets were further categorised in six different topics:

1) Health promotion (including advocacy and health literacy);

2) Health policy and health economics (including tweets related to the economic crisis);

3) Health inequalities (including migrant and ethnic minority health);

4) Public health training, education and research;

5) Communicable/non-communicable diseases;

6) Other (all the tweets not strictly related to the previously mentioned five topics).

All the re-tweets were excluded from our analysis in order to avoid misclassification of topics. Analysis were performed using STATA V.11 (Stata Corp, College Station, Texas, USA, 2011) showing percentages for dichotomic and categorical variables, and mean and standard deviations for continuous variables.

\section{Results}

\section{Tweets statistics}

A total of 1067 tweets with the hashtag \#ephglasgow were retrieved. Table 1 describes the main characteristics of the tweets collected. The most part were tweeted during the four days of the conference (921 - 86.3\%), while 102 (9.6\%) were published before the conference (21 July - 18 November 2014) and 44 (4.1\%) in the ten days after. A total of 209 single accounts tweeted using the hashtag \#ephglasgow, for an average of 5.6 tweets per account. Considering only the 921 messages tweeted during the conference, the highest number of these (288 - 31.3\%) were sent on Friday 21 November 2014, and the lowest number (155 $-16.8 \%$ ) on Wednesday 19 November, the day in which only pre-conferences were organised. 
The overwhelming majority of the tweets retrieved were in English, while only eight were written in other languages. Pictures were present in around one third of the tweets (29.7\%) while external links were published in $13.8 \%$. It must be noted that almost $90 \%$ of the "scientific promotional" tweets included an external link, compared with the $4 \%$ of the "conference-related tweets". (Data not shown).

Around half of the messages mentioned at least a twitter account (by using the symbol@).Conference speakers were mentioned in around one-third of the tweets. Among these, if we consider only the conference-related tweets, nearly $50 \%$ mentioned a speaker.

\section{Tweets' "popularity"}

The popularity of each tweet was assessed through the number of re-tweets and "favourites" (Table 1). The mean of the re-tweets was $1.55 \pm 0.18$ (range 0 -52) while the mean of "favourites" was $0.79 \pm 0.08$ (range 0 13). The tweet with the highest number of re-tweets was written by the actual president of the European Public Health Association, Prof. Martin McKee, while the one with more "favourites" described a sarcastic flow chart for asking questions at a conference (Data not shown).

The most active account, with a total of 72 tweets, was the one of Vesna Bjegovic, president of the Association of Schools of Public Health in the European Region (ASPHER), followed by the official account of the EPH Conference with 40 tweets (Figure 1). The most mentioned account was, as expected, @ EPHConference (165 times) while the second one was @ASPHERoffice, official account of ASHPER (Figure 1).

\section{Qualitative analysis of the tweets}

Table 2 shows number and percentages of tweets for each category. Almost $60 \%$ of the tweets had a sessionrelated content (quotes, impressions, comments related to something that was discussed during a specific session of the conference). Social and logistic categories accounted for around $16 \%$ of the total tweets each, while promotional tweets (scientific and non scientific) represented a total of $8 \%$ of posts published. In Table 3, statistics about contents and topics of tweets are reported. Looking at the session-related tweets only, one third had as main topic "Health inequalities and migrant and ethnic minority health", while $20 \%$ were "Health policy and health economics" oriented and 18\% about Public Health education, training and 
research. A relatively small number of tweets were published regarding "Communicable and noncommunicable diseases" (5.4\%).

\section{Discussion}

This paper aimed to describe quantitatively and qualitatively all the tweets that included the official hashtag of the last European Public Health (EPH) Conference in order to evaluate how much Twitter was used during this meeting and who were the most active users. The $7^{\text {th }}$ EPH Conference in Glasgow was attended by over 1500 delegates from 65 countries. The programme consisted of 7 plenary sessions, 16 pre conferences, 47 workshops, 27 oral sessions, 27 pitch sessions and 18 poster walks.

To our knowledge, the present work is the first study analysing statistics and contents of tweets published during a Public Health Conference. Of the 1500 public health professionals and students attended the $7^{\text {th }}$ EPH Conference in Glasgow, only 14\% (209 attendees) were us Twitter Contributors (TC) that used \#ephglasgow hashtag. In another study the proportion of attendees among TC was similarly high, as reported by Awad and Cocchio in a paper about the use of Twitter at a major national pharmacy conference (90.3\% of TC) [15]. A relatively high percentage of tweets ( 10\%) was published before the conference, in many cases to promote specific sessions of the scientific event or to provide logistic information for attendees. Only $25 \%(25 / 102)$ of the tweets posted before the conference was published by the official organizers' accounts, demonstrating a successful and satisfying involvement of attendees.

A third of the tweets included an event-related picture. In many cases the subject of the pictures was represented by slides of ppt presentation of conference speakers, published with the aim of increasing the dissemination of scientific messages and enriching the content of tweets with scientific data and graphs. Interestingly, $14 \%$ of the tweets analysed included an external link. In particular, almost $90 \%$ of the "scientific promotional" tweets included an external link, compared with $4 \%$ of the "conference-related tweets". This difference is easily explainable considering the potential willingness of attendees to promote their work and publications, taking advantage of the official hashtag of the conference. Through this tool, attendees tried to increase the impact of their studies among scientific community. 
The large number of mentions, re-tweets and favourites highlights the function of Twitter as a tool of networking and social connector for scientific professionals. This feature is even more important if we consider the multi-disciplinary and intersectoral structure of the public health field.

Obviously the most part of the tweets were conference-related. This suggests that Twitter could be helpful to increase the level of debate during a conference. This suggestion was previously proposed by other authors, such as Ronald et al. who supposed that "Twitter could improve presentation quality, particularly if speakers were informed of the capabilities of social media and the need of clarity of key messages" or McKendrick et al. who claimed that Twitter use can further reinforce the "real" learning points from each talk or session[20,22,26]. Since Twitter use seems to be related to a positive impact on conference quality, the use of this kind of tool should be encouraged by conference organisers. The European Public Health Association tried to facilitate and promote the use of Twitter and to increase the number of tweets by implementing the Twitter Wall. During plenary sessions, indeed, on the big screen behind the speakers a Twitter timeline containing the hashtag \#ephglasgow was projected and the moderator asked the audience to use Twitter for questions directed to speakers. Two "Twitter Wall moderators" made a "live" selection of all the tweets related to the topic of the session and deleted inopportune and off-topic tweets. The role of the Twitter Wall during the conferences deserves to be further examined in future studies.

The "topic" most tweeted was the following one: "Health inequalities and migrant and ethnic minority health". The preference for this theme can be easily related to the title of the Conference "Mind the gap: Reducing inequalities in health and health care" that oriented the choice of key-note speakers during plenary sessions, and the contact in roundtables and workshops [27].

The biggest contributors in terms of tweets published were the official account of EPH Conference and the president of ASPHER. The relevance given by these associations to social media is in line with what is proposed and implemented by other scientific societies, such as the American Academic of Orthopaedic Surgeons (AAOS) or the Society of Teachers of Family Medicine (STFM) [12-18]. The involvement of attendees in debates and discussion is part of the new strategy of EUPHA which aims to facilitate and activate a strong voice of the public health network by enhancing visibility of the evidence and by strengthening the capacity of public health professionals. Three main objectives of this "EUPHA Strategy 2014-2020", indeed, are: 1 . To be a leading scientific and independent voice in the field of public health and 
health services research and policy; 2. To build capacity and knowledge in the field of public health and health services research with the aim of supporting evidence-informed practice and policy decisions; and 3 . To prepare future generations of engaged and connected public health professionals for their leadership role in public health. The use of social media is a recognized tool to achieve these aims $[28,29]$.

We are aware that this study has some limitations that deserve discussion. First of all, we analysed only the tweets including the hashtag "ephglasgow". This could be reductive and could underestimate the real amount of online discussions about the EPH conference, especially if no hashtag or no official hashtags were used. However, the official hashtag was repeatedly suggested before and during the conference (e.g. on the programme booklet) in order to convey the information flow.

Secondly, we decided to stop the tweets collection ten days after the end of the conference and messages tweeted after this date were not included in our search. Nevertheless, the number of tweets using the hashtag \#ephglasgow drastically decreased just after the conference since the hashtag for the upcoming EPH conference was already launched (\#ephmilan). Finally, we only checked the tweets related to the $7^{\text {th }} \mathrm{EPH}$ Conference and therefore we limit our consideration to this specific scientific event. Further studies are needed to evaluate time trends and to analyse how this social media will change the way the delegates perceive the participation in scientific conferences.

\section{Conclusions}

Social media use, and especially Twitter, during scientific events is a growing phenomenon that allows public health professionals to propose questions to the presenters, to debate about topics of interest, to provide insights about sessions for those who have not attended the conference. In present time, it is mandatory for conference organisers to keep attention and to promote online discussion and knowledge dissemination during conferences. Further studies are needed to highlight the potential and issues of this communication tool and to supply information that can help organisations and societies to build a strategy for social media utilisation. This is particularly important in the public health field where the wide audience of interested people is well suited to the system of dissemination of key-points typical of microblogging tools as Twitter. 


\section{Conflicts of interest}

Fabrizio Bert and Giacomo Scaioli are EUPHAnxt coordinators.

Dineke Zeegers Paget is the executive director of EUPHA and director of the EPH Conference Office. 


\section{References}

1. Oxford Dictionaries: http://www.oxforddictionaries.com/definition/english/social-media Accessed 5 February 2015.

2. Olenski S. Social Media Usage Up 800\% For U.S. Online Adults In Just 8 Years. Forbes 2013: http:/www.forbes.com/sites/steveolenski/2013/09/06/social-media-usage-up-800-for-us-onlineadults-in-just-8-years/ Accessed 5 February 2015.

3. Bert F, Giacometti M, Gualano MR, Siliquini R. Smartphones and health promotion: a review of the evidence. J Med Syst 2014;38(1):9995.

4. Twitter. About: https://about.twitter.com/company Accessed 5 February 2015.

5. Rocheleau M, Sadasivam RS, Baquis K, et al. An observational study of social and emotional support in smoking cessation twitter accounts: content analysis of tweets. J Med Internet Res 2015;17(1):e18.

6. Reavley NJ, Pilkington PD. Use of Twitter to monitor attitudes toward depression and schizophrenia: an exploratory study. PeerJ 2014;2:e647.

7. Forgie SE, Duff JP, Ross S. Twelve tips for using Twitter as a learning tool in medical education. Med Teach 2013;53(1):8-14.

8. Lee JL, DeCamp M, Dredze M, Chisolm MS, Berger ZD. What are health-related users tweeting? A qualitative content analysis of health-related users and their messages on twitter. J Med Internet Res 2014;16(10):e237.

9. Mckay M, Sanko JS, Shekhter I, Birnbach DJ. Twitter as a tool to enhance student engagement during an interprofessional patient safety course. J Interprof Care 2014;28(6):565-7.

10. Bik HM, Goldstein MC. An introduction to social media for scientists. PLoS Biol 2013;11(4):e1001535.

11. Twitter. Using hashtags on Twitter: https://support.twitter.com/articles/49309-using-hashtags-ontwitter\#. Accessed 10 February 2015.

12. Mishori R, Levy B, Donvan B. Twitter use at a family medicine conference: analyzing \#STFM13. Fam Med 2014;46(8):608-14. 
13. Radmanesh A, Kotsenas AL. Social Media and Scientific Meetings: An Analysis of Twitter Use at the Annual Meeting of the American Society of Neuroradiology. AJNR Am J Neuroradiol 2014. [Epub ahead of print]

14. Wilkinson SE, Basto MY, Perovic G, Lawrentschuk N, Murphy DG. The social media revolution is changing the conference experience: analytics and trends from eight international meetings. BJU Int 2014. doi: 10.1111/bju.12910. [Epub ahead of print]

15. Awad N, Cocchio C. Use of Twitter at a major national pharmacy conference. Am J Health Syst Pharm $2015 ; 72(1): 65-9$.

16. Cochran A, Kao LS, Gusani NJ, Suliburk JW, Nwomeh BC. Use of Twitter to document the 2013 Academic Surgical Congress. J Surg Res 2014;190(1):36-40.

17. Ferguson C, Inglis SC, Newton PJ, Cripps PJ, MacDonald PS, Davidson PM. Social media: a tool to spread information: a case study analysis of twitter conversation at the Cardiac Society of Australia \& New Zealand 61st annual scientific meeting 2013. Collegian 2014;21(2):89-93.

18. Gornés D, Rodríguez-Roiz JM, Fernández-Valencia JA. Social media in orthopaedics: a case study analysis of twitter posts at the American Academy of Orthopaedic Surgeons (AAOS) Congress 2012 and the European Federation of National Associations of Orthopedics and Traumatology (EFORT) Congress 2012. IJAJR 2014;1:17-19.

19. Loeb S, Bayne CE, Frey C, et al. Use of social media in urology: data from the American Urological Association (AUA). BJU Int 2014;113(6):993-8.

20. McKendrick DR, Cumming GP, Lee AJ. Increased use of Twitter at a medical conference: a report and a review of the educational opportunities. J Med Internet Res 2012;14(6):e176.

21. Neill A, Cronin JJ, Brannigan D, O'Sullivan R, Cadogan M. The impact of social media on a major international emergency medicine conference. Emerg Med J 2014;31(5):401-4.

22. Roland D, May N, Body R, Carley S, Lyttle MD. Are you a SCEPTIC? SoCial mEdia Precision \& uTility In Conferences. Emerg Med J 2014. pii: emermed-2014-204216. [Epub ahead of print]

23. European Public Health (EPH) Conference - Glasgow 2014: http://ephconference.org/conferenceglasgow-2014-149 Accessed 10 February 2015.

24. European Public Health Association (EUPHA): http://www.eupha.org/ Accessed 12 February 2015. 
25. Twitter: www.twitter.com Accessed 10 February 2015.

26. McKendrick DR. Smartphones, Twitter and new learning opportunities at anaesthetic conferences. Anaesthesia 2012;67(4):438-439.

27. European Public Health (EPH) Conference: http://www.ephconference.eu/ Accessed 12 February 2015.

28. Zeegers Paget D, Barnhoom F, Masic I. EUPHA STRATEGY 2014-2020. Mater Sociomed 2014; 26(6):422-426.

29. Bert F, van der Star A, Scaioli G. Next generation of public health professionals: networks and the EUPHAnxtintegration approach. Eur J Public Health 2014;24(6):876. 
Table 1. Quantitative analysis of the tweets that used the hashtag \#ephglasgow ( $N=1067)$

\begin{tabular}{|c|c|c|c|}
\hline & & \\
\hline & & $\mathbf{N}$ & $\%$ \\
\hline \multirow[t]{3}{*}{ Date } & Before the conference & 102 & 9.6 \\
\hline & During the conference & 921 & 86.3 \\
\hline & After the conference & 44 & 4.1 \\
\hline \multirow[t]{2}{*}{ Pictures } & Yes & 317 & 29.7 \\
\hline & No & 749 & 70.3 \\
\hline \multirow[t]{2}{*}{ Links } & Yes & 147 & 13.8 \\
\hline & No & 919 & 86.2 \\
\hline \multirow[t]{2}{*}{ Language } & English & 1058 & 99.2 \\
\hline & other & 8 & 0.8 \\
\hline \multirow[t]{2}{*}{ Mentions (@) } & Yes (one or more) & 561 & 52.6 \\
\hline & no & 505 & 47.4 \\
\hline Retweets & & $1.55^{\mathrm{a}}$ & $\pm 0.18^{\mathrm{b}}$ \\
\hline Favourites & & $0.79^{\mathrm{a}}$ & $\pm 0.08^{\mathrm{b}}$ \\
\hline \multirow[t]{2}{*}{ Speaker mention } & Yes & 354 & 33.2 \\
\hline & No & 712 & 66.8 \\
\hline
\end{tabular}


1

2

3

4

5

6

7

8

9

10

11

12

13

14

15

16

17

18

19

20

21

22

23

24

25

26

27

28

29

30

31

32

33

34

35

36

37

38

39

40

41

42

43

44

45

46

47

48

49

50

51

52

53

54

55

56

57

58

59

60

Table 2. Number and percentages of tweets for each category $(\mathrm{N}=1067)$

\begin{tabular}{lcc}
\hline Tweet category & $\mathbf{N}$ & $\mathbf{\%}$ \\
\hline Conference-related & 628 & 58.9 \\
Social & 175 & 16.4 \\
Logistic & 168 & 15.8 \\
Promotion & 37 & 3.5 \\
Scientific promotion & 46 & 4.3 \\
& & \\
other & 12 & 1.1 \\
\hline
\end{tabular}

http://mc.manuscriptcentral.com/spub E-mail: sjpheditorial@sagepub.com 
Table 3. Number and percentages of conference-related tweets for each main topic $(\mathrm{N}=628)$.

\begin{tabular}{lcc}
\hline Topic & $\mathbf{N}$ & $\mathbf{\%}$ \\
\hline Health promotion, advocacy, health literacy & 82 & 13.0 \\
Health policy and health economics & 130 & 20.7 \\
Health inequalities and migrant and ethnic minority health & 192 & 30.6 \\
Public Health education, training and research & 111 & 17.7 \\
Communicable and non-communicable diseases & 34 & 5.4 \\
Other & 79 & 12.6 \\
\hline
\end{tabular}




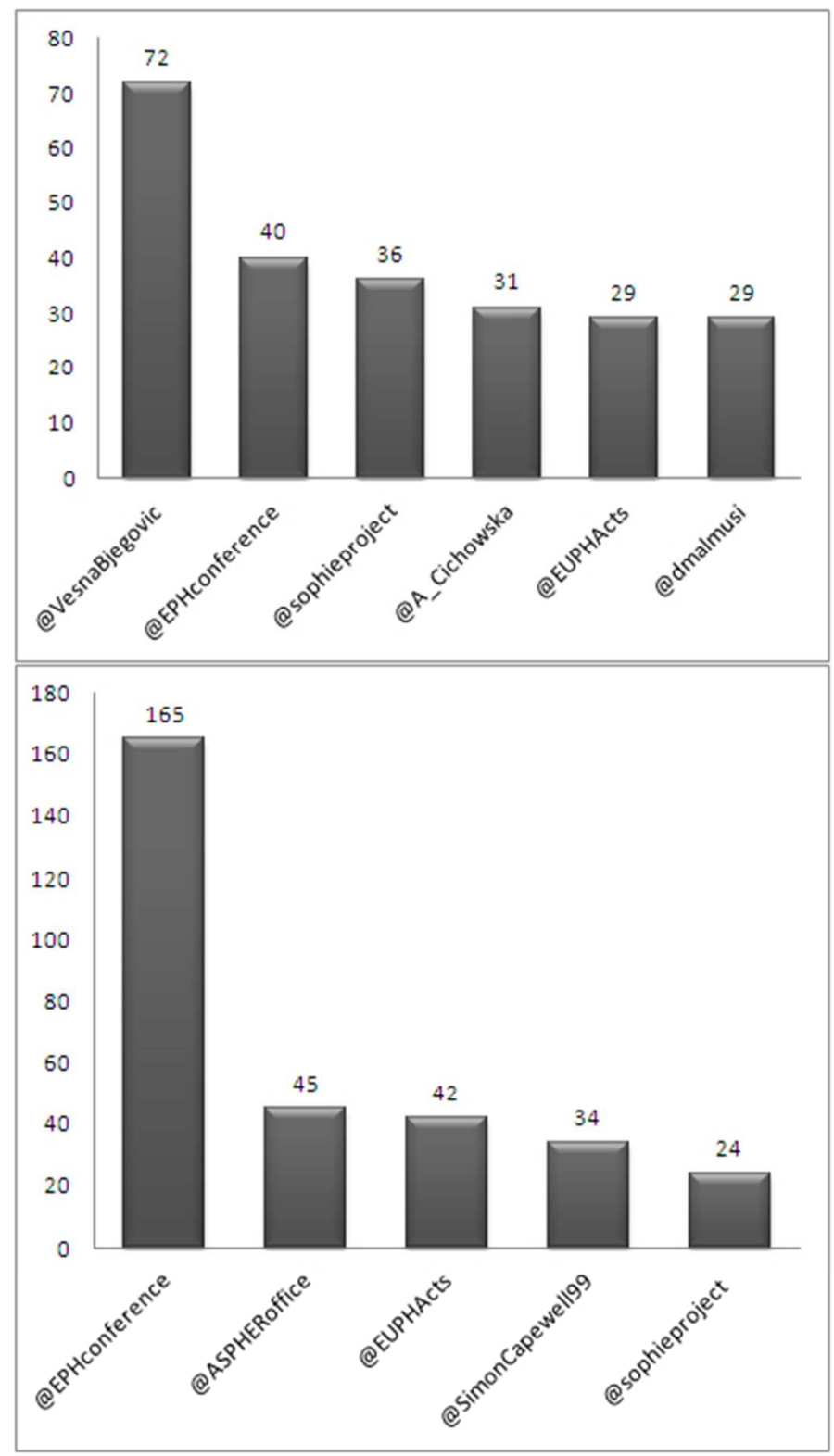

Figure 1. Most prolific and most mentioned accounts. $113 \times 200 \mathrm{~mm}(96 \times 96$ DPI) 